\title{
The Diffusion of Inclusion: An Open Polity Model of Ethnic Power Sharing
}

Lars-Erik Cederman $^{1}$, Kristian Skrede Gleditsch ${ }^{2,3}$, and Julian Wucherpfennig ${ }^{4}$

\author{
${ }^{1}$ ETH Zurich \\ ${ }^{2}$ University of Essex \\ ${ }^{3}$ Peace Research Institute Oslo (PRIO) \\ ${ }^{4}$ Hertie School of Governance
}




\begin{abstract}
While there is a growing consensus that ethnic inclusion produces peace, less is known about what causes transitions to power sharing between ethnic groups in central governments in multiethnic states. The few studies that have addressed this question have proposed explanations stressing exclusively domestic factors. Yet, power sharing is spatially clustered, which suggests that diffusion may be at play. Inspired by studies of democratic diffusion, we study the spread of inclusive policies with an "open polity model" that explicitly traces diffusion from inclusion in other states. Our findings indicate that the relevant diffusion processes operate primarily at the level of world regions rather than globally or between territorial neighbors. Thus, the more inclusive the region, the more likely a shift to power sharing becomes. Shifts away from inclusion to dominance are less common since World War II, but they are more likely in regional settings characterized by ethnic exclusion.
\end{abstract}


Ethnic politics matters. Recent studies suggests that ethnically exclusive practices are associated with a series of unfavorable outcomes, including underdevelopment (e.g. Birnir \& Waguespack, 2011), suboptimal provision of public goods (e.g. Cammett, 2011), and even civil war (e.g., Gurr, 2000b; Cederman, Wimmer \& Min, 2010). This scholarship follows in Lijphart's (1977) footsteps, arguing that power sharing helps reduce conflict (e.g., Hartzell \& Hoddie, 2007; Mattes \& Savun, 2009). Moreover, the view that inclusion begets peace is also shared by an increasing number of policy makers.

Inclusive practices have become more frequent over time. Gurr $(2000 b)$ postulates that a new regime of accommodation has spurred a decline of ethnic warfare since the mid-1990s (see also Cederman, Gleditsch \& Wucherpfennig, 2017). At the same time, we also know that the trend toward declining exclusion is not present in all parts of the world, and masks considerable heterogeneity: while some areas have experienced major gains, such as Sub-Saharan Africa, others have seen hardly any improvement at all, as illustrated by the Middle East and North Africa (Cederman, Gleditsch \& Buhaug, 2013, Chap. 3). Furthermore, just as democracies could "back-slide," the surge of populist nationalism that increasingly challenges liberal policies in western democracies and try to undermine international organizations such as the European Union, could turn the recent wave of inclusion into a wave of exclusion.

The fact that inclusion and power sharing, and their opposite, ethnic dominance, appear to be regionally clustered constitutes a puzzle. Since the literature has focused mostly on the consequences of inclusion and exclusion, we know relatively little about why governments choose to include ethnic groups in the first place. A handful quantitative studies attempt to explain such decisions by studying ethnic inclusion as a function of the state's internal characteristics (see e.g. Roessler, 2011; Wimmer, 2015). Yet, these emphasize either largely time-invariant factors (such as ethnic demography) or relatively rare events (such as previous conflict) that fail to account for the clear pattern of clustering. Thus, it may not be enough to explain ethno-political constellations based on 
a "closed-polity" model, and arguments about transnational diffusion are likely to complement such research. Existing studies that have opened up the state in the search for explanations of inclusive practices have either assumed a global diffusion of norms (e.g., Meyer et al., 1997), or limited themselves to specific regions, such as the Balkans (e.g., Mylonas, 2012). In short, we are lacking a systematic study on the transnational determinants of ethnic inclusion.

The literature on democratization has demonstrated explicitly the role of diffusion patterns in relation to internal causes (Gleditsch \& Ward, 2006). Inspired by these approaches, but without equating ethnic inclusion and nation-building with democracy a priori, we investigate to what extent diffusion mechanisms can account for the increase of ethnic inclusion. We do so by assessing whether an open-polity model (OPM) adds explanatory power to the baseline constituted by a closed-polity model (CPM). Accounting for how ethnic dominance gives way to power sharing, and the reverse, our findings indicate that the relevant diffusion processes operate most prominently at the level of world regions rather than globally or between territorial neighbors. The more inclusive the region, the more likely becomes a shift to power sharing. Conversely, shifts away from inclusion to dominance are more likely in regional settings where ethnic exclusion is more common,although there are fewer transitions to exclusion in the post-World War II period and this finding is less certain from a statistical point of view.

The manuscript is structured as follows. We first review existing domestic explanations of inclusion in the literature and build on these to set up the CPM. We then draw on studies covering the diffusion of democracy to develop the propositions for the OPM. The following section introduces our data and explores patterns therein, thus preparing the ground for empirical evaluation of the CPM and the OPM. In addition, we present effect analysis and discuss a number of case illustrations. The concluding section summarizes our results and discusses their importance for theory and policy. 


\section{Explanations of ethnic inclusion in the literature}

Following the lead of Gurr's (2000b) pioneering work, recent studies establish that excluded and disadvantaged ethnic groups are more likely to rebel against the state than politically privileged groups that lack motives to do so (e.g. Petersen, 2002; Cederman, Wimmer \& Min, 2010). Moreover, many find that including ethnic groups helps prevent or end civil war, either through territorial autonomy and decentralization (e.g. McGarry \& O'Leary, 2009) or governmental power sharing (e.g. Lijphart, 1977; Hartzell \& Hoddie, 2007).

Given the importance of inclusive policies for peace and development, understanding the deeper causes and conditions favorable to inclusion is of direct relevance to theory and policy. Yet, what causes shifts between exclusion and inclusion has not attracted nearly as much scholarly attention. Broadly speaking, existing scholarship can be classified as either closed-polity approaches, which seek explanations within the state itself, or open-polity accounts, which explain inclusion as the result of transnational factors and processes. We briefly summarize the closed-polity studies before turning to research that goes beyond purely domestic explanations.

Ethnic diversity plays an important role in explanations of ethnic inclusion, either as a root cause of inclusion, or as an intermediate variable. Either way, the central importance of ethnic diversity for a state coalitions's decisions to include or exclude ethnic groups is intuitive and straightforward. Indeed, in ethnically homogeneous states, the need for ethnic power sharing never arises in the first place. In instances where the population aside from a dominant group is very small and marginal, shifts toward ethno-political pluralism make little sense.

Viewing ethnicity as being inert and deeply rooted in history, primordialist scholarship tends to be pessimistic about the prospects for power sharing, primarily because ethnic cleavages are assumed to be associated with deep mistrust (e.g., Geertz, 1963; Connor, 1994). Modernist theories also assume that ethnic diversity plays a role, but view such patters as products of state formation and 
other political processes, rather than as immutable structures. Adopting an explicitly constructivist perspective, these theories stress how political institutions, including education, language and religious policies in state bureaucracies, contribute to ethnogenesis and assimilation (e.g., Gellner, 1983). European history shows that state-centric nationalism has tended to produce more inclusive, civic identities through assimilation as opposed to unification or separatist types of nationalist mobilization, which are more closely associated with ethnic nationalism (Hechter, 2000). Strong state capacity, then, should be associated with broad trans-ethnic coalitions and successful integration of representatives of minorities into governing elites (Wimmer, 2015).

Other explanations highlight democracy as a source of inclusive politics. Strictly speaking, both democracy and power sharing in multi-ethnic states are about inclusion, although inclusion concerns individuals in the former case, and ethnic groups in the latter case. The main logic stresses that ethnic minorities enjoy more freedom to organize in democracies, and thus cannot be suppressed as easily (e.g. Diamond, 1994). Doing well in political competition in democracies may require a broader support base, and this can encourage coalitions and collaboration across ethnic groups. Thus, it seems reasonable to expect elites in democracies to be less likely to cling to ethnic dominance when there is significant diversity (Gurr, 2000b).

Finally, existing work has implicitly treated ethnic inclusion as a tool of conflict-management, based on either past or anticipated conflict. One important question is whether governments tend to include or exclude ethnic groups that they expect could rebel in the future. For example, Roessler (2011) argues that elites in Africa tend to exclude potential coup-makers even at the risk of triggering peripheral war. Although this logic may apply to some cases, recent research indicates that governments more generally include potentially threatening groups (Wucherpfennig, Hunziker \& Cederman, 2016). Indeed, the literature on post-conflict settlements illustrates that inclusive arrangements are often introduced as a way to prevent recurrent conflict (see e.g. Hartzell \& Hoddie, 2007). 
Having briefly summarized the most prominent closed-polity accounts of ethnic inclusion, we now turn to mechanisms proposed to explain inclusive and exclusive practices in open polities. Clearly, these perspectives are less numerous and influential than those that focus on explanatory factors internal to the state. Generally, this class of explanations tends to trace normative change at the global level toward more inclusive practices. The global polity school of Meyer and collaborators (1997) postulates a sweeping macro-historical process, propagating a "rational world culture" across the globe since the age of the Enlightenment.

At the regional level, explanation of ethnic groups' power access typically show how groups with transnational ethnic kin risk being excluded on grounds that their loyalty is questioned. In a classical study of the "Macedonian syndrome," Weiner (1971) shows how a climate of suspicion and paranoia leads to increasing polarization both within and between Balkan states. Governments will exclude, and possibly even discriminate, groups that are ethnically linked to rival states with which the host state has ongoing rivalries (Mylonas, 2012). However, these conjectures are yet to be tested beyond particular historical cases.

\section{From diffusion of democracy to diffusion of inclusion?}

In order to extend the theoretical and empirical scope, we shift the attention to the democratization literature to establish more depth in terms of possible diffusion mechanisms. This allows us to highlight several important parallels in terms of the drivers of both democracy and inclusion.

Scholars have noted that many of the domestic conditions held to favor democratization change slowly over time or fail to stack up with periods of important transitions, and suggested that the likelihood of a transition in one country changes in response to international factors and events in other states (see e.g. O'Loughlin et al., 1998; Starr, 1991). Moreover, transitions to democracy are not a one-way street, and for much of 20th century forms of autocratic rule such as one-party states 
also appeared to diffuse.

Gleditsch \& Ward (2006) argue that although the specific trajectories of individual transitions are extremely diverse, they can be subsumed under a simple framework focusing on power, mobilization, and the preferences of important actors, where democracy emerges as a rational compromise when no single actor is able to dominate. They relate the diffusion of democracy to how linkages to external actors and events influence the relative distribution of power and the preferences of relevant groups in conflict over political institutions.

Outside actors can promote democratization by providing assistance to reform efforts and undermining autocratic rulers. More generally, external shocks may alter the domestic distribution of power, and the impact is likely to be particularly dramatic when there are shifts and upheavals in neighboring entities and protest emulates efforts elsewhere. Schelling's (1971) "tipping model" and the idea of cascades have often been applied to fall of socialism in Eastern Europe (e.g., Kuran, 1991).

The prospects for democratization also depend on the perceived benefits and costs of particular institutional arrangements. Many powerful actors traditionally resisted democratization over fears of the consequences of unmitigated popular rule (see Muller, 1999). However, resistance declines as elites observe that democracy in other countries did not lead to the expected disastrous outcomes. Moreover, maintaining autocratic rule becomes more costly as other countries democratize and remaining autocrats are more likely to be subjected to sanctions and ostracized as remnants of illegitimate rule. Conversely, the temptation to restrict governmental access is higher in neighborhoods dominated by ethnic exclusion. In general, countries are likely to be judged as particularly bad offenders in terms of violating human rights and discriminatory practices based on how they fare relative to other putatively similar neighboring states (e.g., Bell et al., 2014; Gleditsch \& Ward, 2006).

In principle, the mechanisms highlighted by diffusion scholars in general, and by students of 
democratization in particular, could plausibly also apply to transitions to ethnic inclusion. Successful transitions to inclusion in other states may inspire excluded groups to make similar demands and emulate the strategies of contestation that have proven effective elsewhere. Governing coalitions are also likely to become less resistant to granting inclusion if they observe that the consequences of shifting away from exclusion in other states have been less dire than feared. Finally, states that engage in significant exclusion are more likely to look worse, or stand out more to outsiders, in comparison to other states as exclusion becomes less common in other states they are likely to be compared with. This may in turn translate into sanctions for maintaining exclusion or incentives to offer inclusion in terms of improved relations or acceptance in more discriminating international organizations.

However, there are also some limits to the direct analogies to experiences from democratization. Whereas democratic rule is essentially a universal norm, applicable to all countries, countries are likely to face less uniform expectations about power sharing given variation in ethnic demography, as ethnic inclusion or exclusion requires some degree of diversity in the first place.

\section{The closed-polity and open-polity models}

In this section, we derive a series of testable hypotheses that summarize the theoretical expectations of both the closed-polity and the open-polity perspectives. Rather than levels of ethnic inclusion, we aim to explain the timing of shifts from ethnic dominance to shared rule, and vice versa. We refer to these as inclusive and exclusive shifts respectively. 


\section{Closed-polity hypotheses}

To establish a baseline for these transitions, the first step is to take ethnic diversity into account. Building on our discussion about ethnic homogeneity, we expect ethnically diverse countries to experience more transitions to power sharing than uniform ones. We use low ethnic fractionalization as a proxy for the processes that have created greater ethnic homogeneity. Based on this reasoning, we derive our first pair of hypotheses describing transitions between ethnic dominance and power sharing:

H1a. Ethnic diversity increases the probability of inclusive shifts.

H1b. Ethnic diversity decreases the probability of exclusive shifts.

Our account of the literature reminds us that the link between democracy and power sharing is complex. Clearly, there is no one-to-one relationship between democracy and ethnic inclusion. Some democracies discriminate along ethnic lines, such as Estonia and Israel, while some non-democracies practice extensive power sharing, as illustrated by African cases of ethnic inclusion around charismatic political leaders, such as Omar Bongo in Gabon and Mathieu Kérékou in Benin. Furthermore, stable democracies may be less likely to see change in their demos configurations.Yet, on the whole, it can be expected that the chances of inclusive transitions would be higher in democratic states with competitive elections, and such environments also tend to be characterized by a political culture that supports the willingness to make compromises and seek consensus solutions (Gurr, 2000a,b). To cover transitions in the other direction, we postulate that autocratic polities will typically be more exposed to the risk of coups and political purges that initiate ethnic dominance. Again, we summarize these expectations with a second set of hypotheses:

H2a. Democracy increases the probability of inclusive shifts.

H2b. Democracy decreases the probability of exclusive shifts. 
Work on democratization stresses that transitions to democracy are less difficult when countries have previous experiences with democratic rule, as these imply that institutions and organizations can be reestablished and do not need to be created from scratch (see, e.g., Dahl, 1971; Gleditsch \& Ward, 2006; Huntington, 1991). By analogy, countries that have previously had power sharing can be expected to be more likely to return to such arrangements. Based on historical path-dependence, we would expect that inclusive shifts are more likely in countries with a history of inclusion. Without institutional or normative legacies, power sharing will be more difficult to devise or develop, and proposed arrangements will often run into ideological opposition. Thus, we propose the following two hypotheses:

H3a. Previous inclusion increases the probability of inclusive shifts.

H3b. Previous exclusion increases the probability of exclusive shifts.

Finally, we expect shifts in ethnic power structures to be more likely under political instability or change. Political leader changes provide opportunities for leaders to broaden coalitions, through including other groups, as well as opportunities to impose greater dominance. Based on the extensive literature on power sharing as part of post-conflict settlements, we expect changes toward inclusive arrangements to be especially common in countries that have already experienced, or are currently experiencing civil war. Beyond post-conflict cases, political elites may seek to form grand ethnic coalitions as a way to prevent future conflict. As illustrated by many cases in Sub-Saharan Africa, peace agreements typically try to avoid conflict-inducing "spoiler" effects by embracing inclusive solutions (Stedman, 1997). In other cases, previous conflict may motivate leaders to opt for imposing control through ethnic dominance, as illustrated by Rwanda. We summarize this reasoning with a combined hypothesis:

H4. Political instability increases the probability of both inclusive and exclusive shifts. 


\section{Open-polity hypotheses}

Turning now to the open-polity perspective, we formulate hypotheses at three levels of diffusion, namely globally, between territorial neighbors, and at an intermediate level, within world regions. Each of these levels constitutes a plausible context within which diffusion mechanisms may be operating. For all these settings, we postulate that the external level affects both included and marginalized groups. While dominant ethnic elites come under pressure to open the doors to previously excluded ethnic groups, representatives of groups that are deprived of governmental representation could be encouraged to redress their situation. However, this dynamic could also be reversed if repeated shifts toward higher levels of exclusion inspire further moves toward ethnic dominance.

In principle, decentralized learning and emulation may drive such a process by prompting ethnically exclusive regimes to become more inclusive, but as with democratization, such reforms typically encounter considerable resistance from incumbent power holders. Previously dominant ethnic elites may have much to fear from sharing power with potentially vengeful and assertive counter-elites (Roessler, 2011). In such cases, entirely voluntary mechanisms may not be enough to effect change. Instead, inclusion is more likely to flow from imposed diffusion pressures exerted by external actors, such as international organizations and power states. Motivated by a strong normative commitment and/or by strategic self-interest, these external actors will attempt to influence the behavior of domestic actors, especially the government in question, by appealing to norms, by socializing them, and by setting incentives that reward inclusive behavior while punishing exclusive moves. Again, it is also possible that illiberal powers will try to reward exclusive and discriminatory, rather than liberal, policies by undermining the influence of liberal organizations that are perceived to stand in the way of narrowly ethno-nationalist definitions of "sovereignty."

We start by considering diffusion at the global level. Along the lines of Meyer et al. (1997), it is possible to interpret the increasing adoption of inclusive practices as a part of a world-wide 
emulation of dominant models of governance. To some extent, international organizations, especially the United Nations, could drive such a trend through incentives and sanctions, but Meyer et al.'s argument stresses a more informal mechanism that operates primarily through emulation by local elites. Constructivist scholarship has done much to analyze this type of normative evolution with respect to governance forms (see e.g. Dobbin, Simmons \& Garrett, 2006; Finnemore \& Sikkink, 1998). As a part of a general trend toward liberal values in world affairs, such a macro-historical diffusion process, can be expected to trigger shifts to inclusion if the world becomes more inclusive in general (Simmons \& Elkins, 2004). Conversely, an illiberal counter-trend could provoke moves toward ethnically exclusive rule. We formulate these expectations in the following way:

H5a. Higher global inclusion increases the probability inclusive shifts.

H5b. Higher global inclusion decreases the probability exclusive shifts.

Rather than being a truly global phenomenon, the diffusion effect could also be limited to emulation and learning between territorial neighbors. There is considerable heterogeneity across different parts of the world, and this is difficult to reconcile with the idea of universal influences affecting all countries alike. To a large extent, the "Arab Spring" of 2011 illustrates this pattern of diffusion between neighboring states. Starting in Tunisia, the wave of protest against the ruling dictatorships spread like a forest fire from country to country in the Middle East, but had only limited impact in other parts of the world such as East Asia. Previous studies of the diffusion of democracy have typically operationalized and found support for such processes at the level of contiguous states (Kopstein \& Reilly, 2000; Gleditsch \& Ward, 2006). Subscribing to a similarly decentralized approach to diffusion, Kuran (1998) proposes a model of "dissimilation" that explains how an ethnicization of politics leads to divergent identification patterns spreading across state borders through demonstration effects and reputational mechanisms.

In order to instrument for power sharing, Cammett \& Malesky (2012) assume that such institutions tend to spread in states' geographic neighborhoods. To our knowledge, their study is 
the only example of a formal investigation of diffusion of power sharing, although the diffusion mechanism is primarily introduced for methodological purposes, rather than being defended as a central theoretical component in their argument. Again, it is reasonable to expect the mechanism to operate both in expanding and contracting inclusion. Indeed, there may also be "countervailing incentives" that demonstrate how ethnic inclusion may spread based on negative experiences with exclusion or positive experiences with inclusion (see e.g. Fearon, 1998, 112-113). As authoritarian neighborhoods are likely to hamper democratization, the same would hold for the adoption of inclusive practices and institutions.

Thus, we postulate a neighborhood-level version of our diffusion account according to which the adoption of power sharing in one country sets the incentives for both governments and representatives of excluded groups to follow suit in neighboring states. In principle, such a diffusion scenario could be compatible with imposed diffusion, especially in case of asymmetric neighborhood relations involving powerful states. Yet, the most likely setting features voluntary learning or emulation. Again, we summarize our expectations with a pair of hypotheses:

H6a. Higher neighborhood inclusion increases the probability inclusive shifts.

H6b. Higher neighborhood inclusion decreases the probability exclusive shifts.

Finally, we consider the possibility that the relevant diffusion mechanisms occur between countries in broader regions or groupings that are larger than states' immediate geographical neighborhoods, but more confined than the global level. Rather than diffusing evenly, "modular" political phenomena tend to spread among regions or states that share common institutional, historical and cultural characteristics (Beissinger, 2007). There are many possible ways to identify distinct regions in the international system, including structural similarity (e.g., similar language ot regime type), formal organizations (e.g., the OECD), and geographical proximity between states. In an early study of regions in world politics, Russett (1967) examined clustering in political, social and economic characteristics through factor analysis to identify how countries map into similar 
regional groupings. To a large extent, the regions derived tend to be clearly geographically confined, reflecting the common history and origins of conventional world regions. Moreover, interactions tend to be higher among proximate states (Bergstrand, 1985), and formal organizations without universal membership are often defined on a regional basis (Powers \& Goertz, 2011). As such, we focus on conventional definitions of geographical regions.

In the case of democratization, diffusion has followed wavelike processes that are mostly confined to specific world regions that exhibit such similarities, such as Southern Europe, Eastern Europe or Latin America (Huntington, 1991). Focusing on “democratization from above," Pevehouse (2005) argues that regional organizations reinforce such a process by legitimizing transitional regimes and by imposing pressure on elites in authoritarian member states, who may also feel reassured enough by organizational protection to acquiesce to the transition process.

We propose that larger geographic regions constitute important reference categories for the diffusion of inclusion as well. Drawing on Pevehouse's theory, a first set of causal mechanisms postulates that regional organizations use targeted policies to pressure or entice incumbent regimes to become more ethnically inclusive, through incentives, persuasion and socialization that prompt change and lock it in through institutional safeguards. While the goal of ethnic inclusion is typically an explicit principle of the organization itself, the actual compliance with the norm among the member states is crucial for this type of regional spread. As in the case with democracy, world regions diverge drastically in their level of ethnic inclusiveness and so do the regional organizations themselves. The degree of interventionism in the area of minority politics varies from stronger norms of non-interventionism, as illustrated by the Association of Southeast Asian Nations (ASEAN), to more interventionist organizations, such as the European Union and the African Union.

In addition to "inclusion from above" through formal institutions, there is a second set of more informal mechanisms that operates at least partly without the direct support of regional organizations. In such cases, early and successful adopters are likely to take the lead in promoting inclusive norms, 
usually due to a combination of moral commitment and strategic self-interest in order to lock in the reforms in the original adopting country (Spruyt, 1994; Beissinger, 2007). Post-Apartheid South Africa illustrates how a pioneering state is inclined to externalize its own success story by promoting power sharing as a solution in post-conflict situations.

On the receiving side, the effectiveness of diffusion depends crucially on the compatibility of the diffusing norms with local habits and inclinations (Acharya, 2004). Mehler (2016) argues that the adoption of inclusive practices depends both on norm-infusing external actors and the receiving actor, in this case the incumbent government. In world regions, such as Africa, where power sharing is compatible with the traditional, paternalistic governance styles, we can expect inclusive practices to spread more readily than in areas that are more strongly committed to ethnic nationalism. For example, Rothchild \& Foley (1988) report that "political incorporation of all major social interests" constitutes the main approach to politics in most African states.

As is the case with the consolidation of democracy (Pevehouse, 2005, Chap. 6), regional institutions also contribute to preventing reversals away from ethnic inclusion. If key members' commitment to inclusion wavers, thus weakening the organization's influence, an illiberal snow-ball process could be set in motion that would create a region-wide return to exclusive ethno-nationalism that triggers a general shift toward exclusive policies and possibly even discrimination of ethnic minorities.

We summarize our theoretical expectations at the regional level with a final pair of hypotheses:

H7a. Regional inclusion increases the probability inclusive shifts.

H7b. Regional inclusion decreases the probability exclusive shifts. 


\section{Conceptualizing and measuring ethnic inclusion}

Having laid out our theoretical conjectures about the factors and processes driving shift to and away from ethnic inclusion, in this section we introduce our main data sources. We also present some descriptive statistics that highlight important variation across space and time. Our measure of ethnically inclusive regimes is based the Ethnic Power Relations (EPR) data, which provide an encompassing list of 819 politically relevant ethnic groups in sovereign states with a population of at least 500,000, from 1946 until to 2013 (Cederman, Wimmer \& Min, 2010). For each group, the data codes relative size as a share of the country's total population, as well as access to state power at the national level in an ordinal manner according to three main categories:

1. The group rules alone.

2. The group shares power.

3. The group is excluded.

The first and the second category differ in whether a single groups holds state power, or whether this is shared between multiple groups. For our analyses we include all country-years in which ethnicity is "relevant" and there is more than one politically relevant group. For example, this excludes countries such as Germany and Sweden, where ethnicity is never deemed to be politically relevant. ${ }^{1}$

Based on the EPR data, we define ethnic inclusion at the state or country level based on whether power is shared between two or more ethnic groups. More specifically, a country with two or more groups sharing power (as either junior or senior partners) is considered to have inclusion. Likewise, a country is considered to have exclusion if the state is controlled by a single group. The measure is

\footnotetext{
${ }^{1}$ However, countries can also move from a situation with politically relevant ethnic groups to ethnicity deemed irrelevant (e.g., Cuba, 1960), or politically relevant ethnic groups can emerge in countries where ethnicity has previously been considered irrelevant (e.g., Brazil 2003).
} 
binary in that countries either have inclusion or exclusion. However, a country with inclusion or power sharing could still have additional individual groups that remain inclusion. ${ }^{2}$

We first examine the proportion of states with inclusion as defined above over the period 1946-2013. The upper panel in Figure 1 indicates the proportion included for for all countries, suggesting a clear increase over time. Although the population of states also changes over the period, especially with the introduction of new independent states during decolonization, we see a similar positive trend if we focus only on countries in continuous existence since 1946 (see supplementary appendix).

The lower panel in Figure 1 plots the actual transitions between states in individual countries to/from inclusion over time. This does not suggest a simple pattern, where all transitions cluster in specific time periods, although there is some evidence for a peak in transitions away from inclusion in the 1960s and 1970s and a larger number of transitions to than away from inclusion in the post-Cold War period. Over the entire period we have 44 transitions from exclusion to inclusion and 18 transitions from inclusion to exclusion. (see the online appendix for a full list of all transitions). ${ }^{3}$

The global trends mask considerable geographical variation and differences across regions. Mapping the spatio-temporal distribution of inclusion provides an overview of the variation across space and time. Figure 2 depicts four global snapshots. It is clear from this that there has been a clear increase in inclusion and shifts away from ethnic dominance among African states and to some extent Latin America as well. However, in other regions such as Europe we have seen far fewer

${ }^{2}$ We have also considered an alternative measure of inclusion further requiring that power sharing must encompass at least $50 \%$ of the population of relevant groups. In practice, however, power sharing involving less than $50 \%$ of the population (inclusive minority rule) tends to be rare, and only one such case exist in 2013, namely Nepal, where the included groups are just short of $50 \%$. In other words our results do not change much with a stricter size requirement, and we focus only on the simple power sharing measure here.

${ }^{3}$ Beyond changes for individual group the EPR data also allow for changes in the group composition, but only 11 transitions to/from inclusion coincide with such group changes. Notably, in the 1994 transition in South Africa, Blacks as an excluded group is transformed into 9 distinct included groups. 


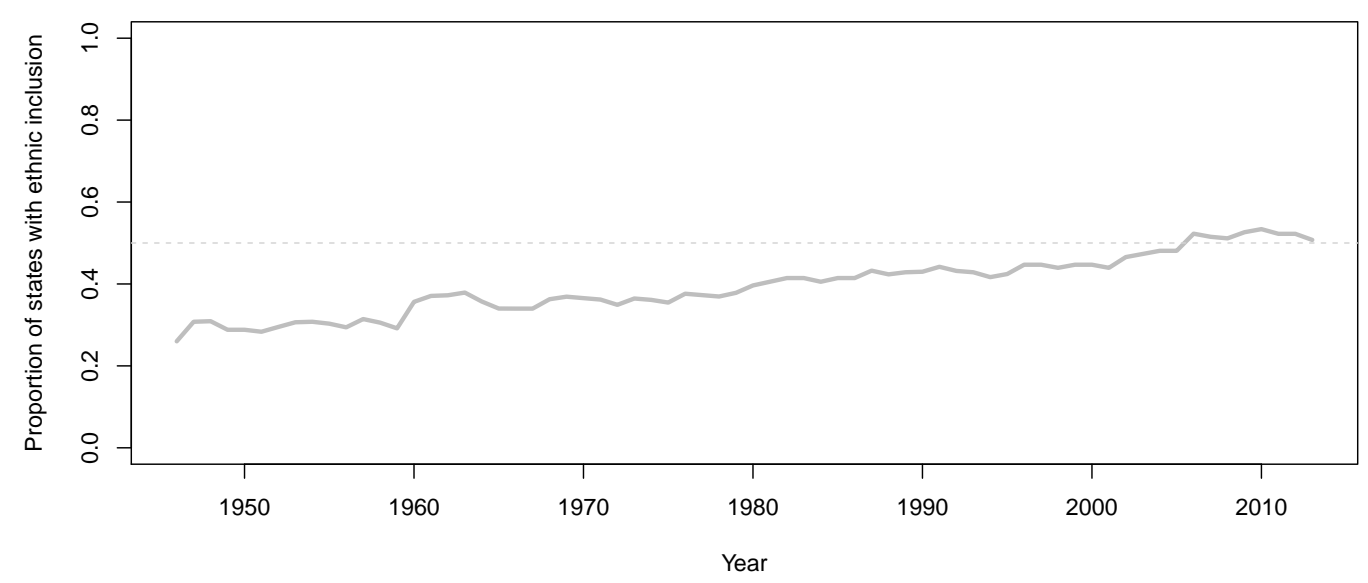

(a) Proportion included

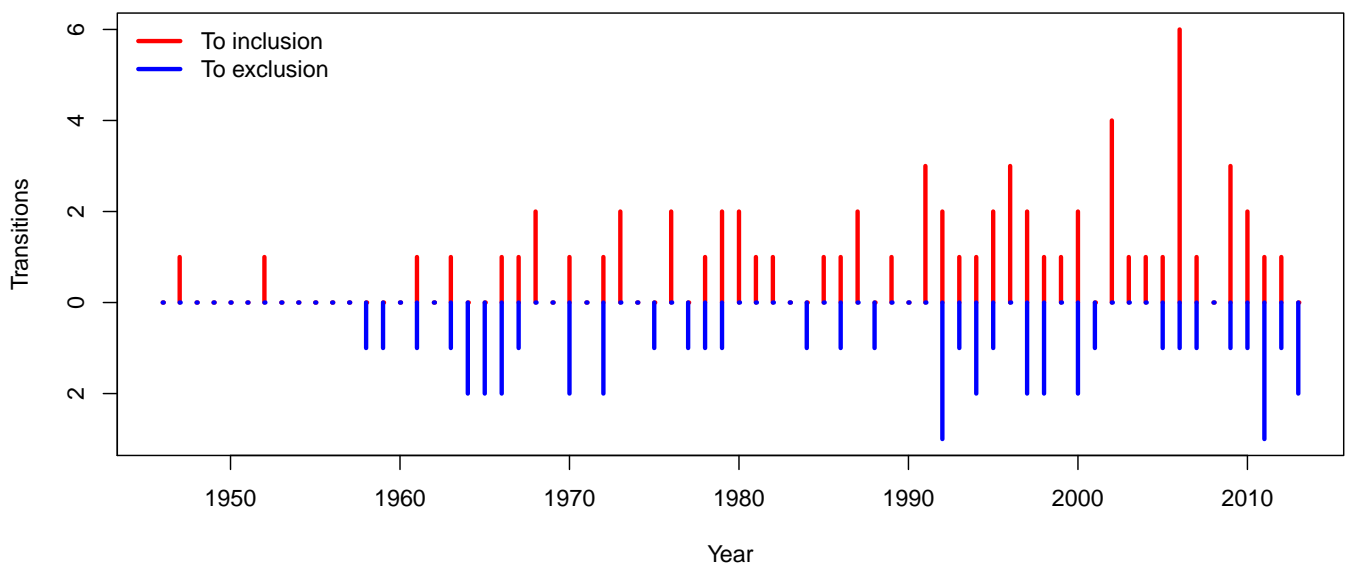

(b) Transitions to/from inclusion

Figure 1: Trends in ethnic inclusion, 1946-2013

changes. The maps indicate spatial clustering within these broader geographical regions at specific time points, as countries with inclusion tend to be surrounded by other countries with inclusion and changes in places with exclusion appear to take place on a geographically clustered basis, with groups of contiguous countries likely to change status between different time periods. 
Figure 2: Ethnic inclusion and exclusion, 1950-2010

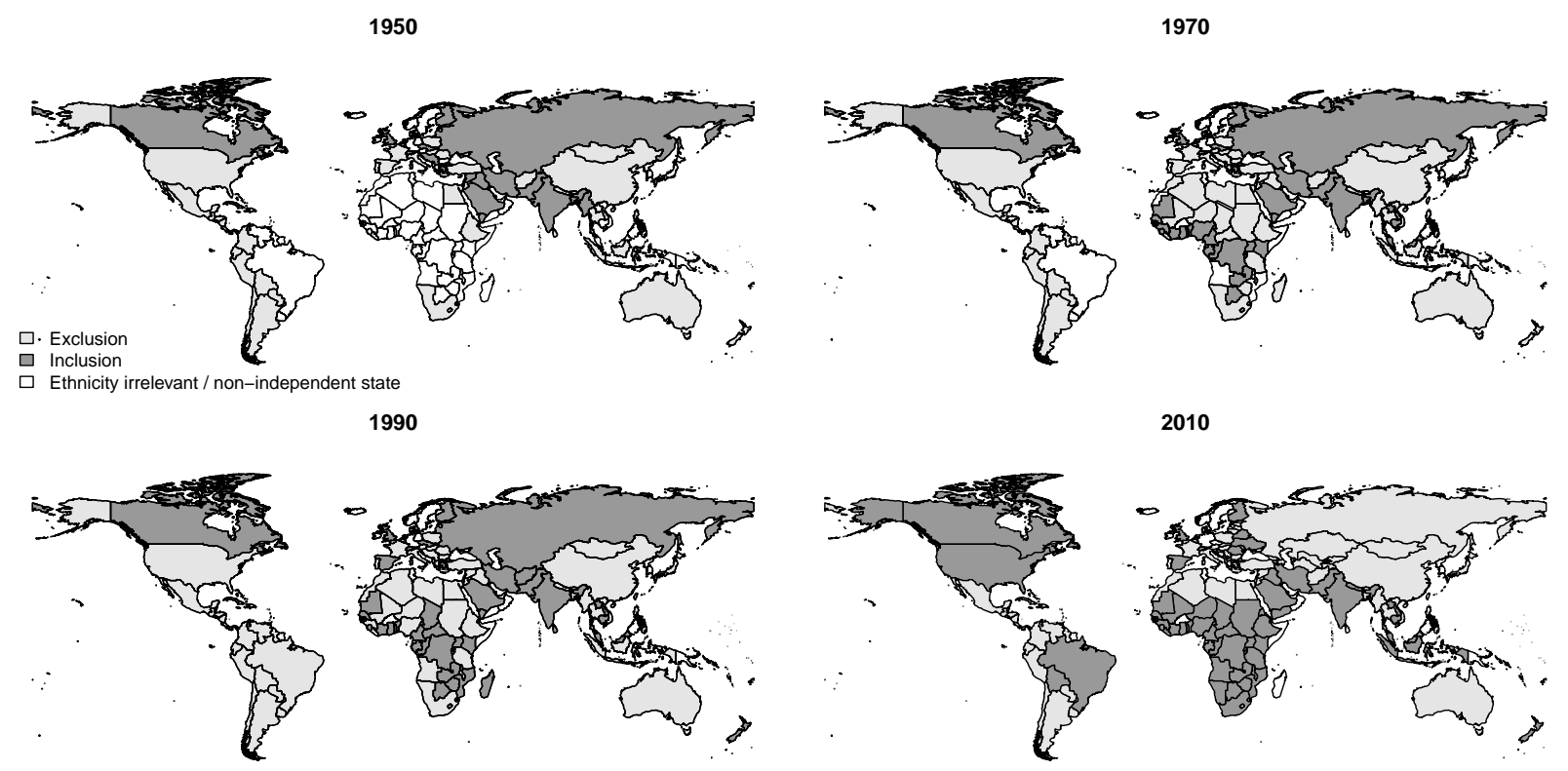

Before delving into our empirical analysis, we also look at the relationship between our inclusion vs. exclusion measure and other types of political representation and status. It is straightforward to show that inclusion is not simply synonymous with political democracy. Inclusion is slightly more common than democracy over the whole period (45\%) than democracy $(36 \%),{ }^{4}$ Exclusion is more common among non-democracies, but even for democracies the countries with inclusion remain in a minority over the period. Indeed, across our sample, just over half of the observations (53.4\%) are on the diagonal of the table, attesting to how we see many cases of inclusion outside democratic regimes and many ethnically exclusionary democracies. In short, inclusion is different from political democracy.

Ethnic inclusion can be more or less encompassing, and ethnic dominance can be more or less exclusionary. However, the density distribution of inclusion for the share of included population

\footnotetext{
${ }^{4}$ We define democracy as having a value of 6 or above on the 20 point Polity scale, see Jaggers \& Gurr (1995). In the online appendix we consider alternative democracy measures and show more formally that the lack of a clear relationship between political democracy and inclusion is not an artifact of the specific measure used here.
} 
Table 1: Ethnic inclusion and regime type

\begin{tabular}{lcc}
\hline & Exclusion & Inclusion \\
\hline Non-Democracy & 2745 & 1854 \\
Democracy & 1495 & 1096 \\
\hline
\end{tabular}

across democracies, non-democracies, countries with power sharing, and countries with dominance by a single group all have a clear peak in the upper end of the distribution, indicating that the included groups tend to be numerically large and that the excluded population share tends to be relatively small in all countries (see online appendix). However, non-democracies and countries without power sharing regimes have a smaller peak at the high end a more noticeable tail over lower values of inclusion toward the left.

\section{Operationalizing the Closed and Open Polity Models}

Before turning to the OPM, we need to establish an analytical baseline, which is the task of the CPM. Our derivation of hypotheses from the CPM identifies classes of properties that are likely to shape exclusion and the resistance or willingness to transition to a power sharing regime, such as ethnic demography, political institutions, security and conflict.

Under the heading of H1a,b, we have argued that more diverse countries should be more likely to see demand for power sharing than less diverse countries, and the value/cost of accepting/resisting such agreements should also depend on diversity. For our measure of ethnic demography we use the fractionalization (ELF) index as a simple measure of the diversity of a country, based on the Herfindahl-Hirschman index (Hirschman, 1964). More specifically, the ELF index is defined as

$1-\sum_{i=1}^{N} p_{i}^{2}$, where $p_{i}$ is a measure of relative size as a proportion of all the $N$ groups in a country. Higher values indicate a more heterogenous population, split among a larger number of significant groups. Low values indicate lower heterogeneity, as a single large group $p_{i}^{2}$ approaches one, or very 
small groups have only a limited impact on the overall index value. We measure group sizes using shares in the EPR data, after normalizing so that all politically relevant groups in a country in a given year sum to $1 .^{5}$

According to $\mathrm{H} 2 \mathrm{a}$, democratic institutions and political competition should also increase willingness to power sharing and decrease resistance, and vice versa (H2b). To operationalize democracy, we consider whether a country has democratic political institutions, using a binary indicator of whether the country has a Polity value of 6 and above. We use values at the beginning of the year, based on the Polity $4 d$ data, since the EPR data look at the ethnic-power relations in place on 1 of January of each year.

Transitions may be more or less likely, depending on previous trajectories or consolidation effects (see $\mathrm{H} 3 \mathrm{a}, \mathrm{b})$. We consider a binary measure indicating whether a country has previously had inclusion or a power sharing regime up to $t-1$ for transitions to inclusion (and previous exclusion for transitions to inclusion). We further also consider the length at time at the observed state at $t-1$, entered as a cubic specification to allow for a non-monotonic relationship (Carter \& Signorino, 2010).

Finally, in order to evaluate H4, we consider two measures for political instability. First, we look at whether countries experienced a change in the leader in the prior year, based on the Archigos data (Goemans, Gleditsch \& Chiozza, 2009). Second, we look at two measures indicating violent civil conflict. We flag all post-conflict periods, where a country has previously seen an ethnic civil war, based on the ACD2EPR data linking the actors in the Uppsala Armed Conflict data to ethnic

${ }^{5}$ We have also considered a number of other plausible measures of ethnic demography and political status, including the overall number of groups, the number of excluded groups, share included population, as well as a possible non-monotonic relationship with fractionalization. However, as can be seen from the results presented in the supplementary appendix, all of these fail to improve the fit of the model of transitions from exclusion to inclusion over a model with the simple fractionalization measure. Many criticisms of the ELF measure in studies of conflict are not directly relevant here, since we look at different outcome, i.e., inclusion. 
groups in the EPR data through ethnic claims on behalf of specific groups (Wucherpfennig et al., 2012). We also consider whether a country has an ongoing ethnic civil war. ${ }^{6}$

Ethnic inclusion may also be affected by various other country characteristics such as the level of development or country size that may also be spatially clustered. We thus consider a country's GDP per capita and population size, using the most recent version from the Expanded Trade and GDP data (Gleditsch, 2002). We log the absolute values, as we would expect the impact to be proportional to the base so that the impact of a given absolute difference should be relatively less important with higher base values.

The features above together constitute the CPM, in the sense that they only consider features within individual countries. We then compare this to the OPM that captures how the likelihood of transitions depend on inclusion and power sharing in other states. We analyze connections at all three levels, referring to $\mathrm{H} 5 \mathrm{a}, \mathrm{b}, \mathrm{H6a}, \mathrm{b}$ and $\mathrm{H7a}$,b respectively. The global level encompasses all other countries in the world, and our measure for a given country $i$ indicates the global proportion of all other countries in the world, expect for $i$ itself. We then consider a measure of inclusion for other states within a country's geographic region, separating between the Americas, Europe, Sub-Saharan Africa, Middle East and North Africa, Asia, and Oceania. ${ }^{7}$ Finally, we consider the share of inclusion among neighboring countries, using a $500 \mathrm{~km}$ buffer around the outer boundaries of a state based on the Cshapes data (Weidmann, Kuse \& Gleditsch, 2010).

We recognize that the distinction between internal and external factors is slightly ambiguous here, since many of the internal factors emphasized in the close polity model may themselves reflect international factors, such as democracy, political development, and even civil war. However, a

\footnotetext{
${ }^{6}$ We have also considered the length of time that a country has remained at peace, either since a previous conflict or independence. However, we found that this did not appear to make a notable contribution after considering the other conflict and security related measures, and do not report this result here.

${ }^{7}$ This is consistent with the operational definition of region used in other studies, e.g., Pevehouse (2005).
} 
comparison of the two models will allow us to examine to what extent levels in other states appear to have an additional influence on transitions, once we consider domestic factors.

It is now time to consider how specific factors affect the likelihood of transitions from exclusion to inclusion and vice versa. We rely on a two-way transition model between binary states, similar to the models used in studies of transitions to and from democracy. In brief, we estimate the likelihood of one state conditional on the previous state in two separate models, that is,

$$
\operatorname{Pr}\left(y_{i, t}=1 \mid y_{i, t-1}=0\right)=\frac{1}{1+e^{-} \mathbf{X} \beta}
$$

and

$$
\operatorname{Pr}\left(y_{i, t}=0 \mid y_{i, t-1}=1\right)=\frac{1}{1+e^{-} \mathbf{X} \gamma} \cdot{ }^{8}
$$

\section{Empirical results}

We first estimate the CPM. The first column in Table 2 displays the estimates of a model of transitions to inclusion in a country with exclusion at time $t-1$ while the second column displays the estimates for transitions from inclusion to exclusion. It is clear from comparing the results in the two columns that the estimates from transitions in one direction are not simply the mirror image of transitions in the other direction. ${ }^{9}$ We comment first on the estimates for transitions to inclusion.

As expected by H1a, we find a significant positive coefficient for the ELF index in the first column, indicating that transitions to inclusion are more likely in more diverse countries. For

\footnotetext{
${ }^{8}$ This transition model can also be estimated as a single equation with interaction terms between the right hand side covariates and lagged values. However, since the variance in limited dependent variables must be assumed for identification, joint estimation and separate models will yield identical results.

${ }^{9}$ More technically, although the coefficients in a model predicting $\operatorname{Pr}\left(y_{i, t}=1\right)$ and $\operatorname{Pr}\left(y_{i, t}=0\right)$ by definition would be symmetric (since one event is simply the inverse of the other), this it is not the case for a first order transition model between states from $t-1$ to $t$. Note that the samples are defined by state at $t-1$, and thus differ, and we can have more transitions in one direction than the other.
} 
Table 2: Closed Polity Model of Transitions

\begin{tabular}{|c|c|c|}
\hline & \multicolumn{2}{|c|}{ Dependent variable: } \\
\hline & $\begin{array}{l}\text { Trans. to inclusion } \\
\text { (1) }\end{array}$ & $\begin{array}{c}\text { Trans. to exclusion } \\
\text { (2) }\end{array}$ \\
\hline ELF & $\begin{array}{c}2.848^{* *} \\
(0.692)\end{array}$ & $\begin{array}{l}-2.727^{* *} \\
(0.890)\end{array}$ \\
\hline Democracy & $\begin{array}{c}0.071 \\
(0.382)\end{array}$ & $\begin{array}{l}-0.339 \\
(0.384)\end{array}$ \\
\hline Leader change & $\begin{array}{r}2.214^{* *} \\
(0.293)\end{array}$ & $\begin{array}{c}1.673^{* *} \\
(0.333)\end{array}$ \\
\hline Postconflict & $\begin{array}{c}0.456 \\
(0.353)\end{array}$ & $\begin{array}{l}-0.017 \\
(0.403)\end{array}$ \\
\hline Ongoing civil war & $\begin{array}{l}-0.075 \\
(0.495)\end{array}$ & $\begin{array}{c}0.454 \\
(0.561)\end{array}$ \\
\hline Ln GDP pc & $\begin{array}{l}-0.204 \\
(0.165)\end{array}$ & $\begin{array}{l}-0.176 \\
(0.163)\end{array}$ \\
\hline Ln population & $\begin{array}{l}-0.152 \\
(0.119)\end{array}$ & $\begin{array}{l}-0.229 \\
(0.148)\end{array}$ \\
\hline Previous inclusion & $\begin{array}{l}1.808^{* *} \\
(0.369)\end{array}$ & \\
\hline Previous exclusion & & $\begin{array}{c}0.381 \\
(0.383)\end{array}$ \\
\hline Constant & $\begin{array}{c}-3.762^{*} \\
(1.783)\end{array}$ & $\begin{array}{c}0.402 \\
(1.857)\end{array}$ \\
\hline Observations & 3,447 & 2,602 \\
\hline Log Likelihood & -226.284 & -178.480 \\
\hline Akaike Inf. Crit. & 476.568 & 380.959 \\
\hline
\end{tabular}

democracies we find a positive coefficient suggesting that these are more likely to see transitions, but this effect is not statistically significant at conventional levels, thus offering only weak support for $\mathrm{H} 2 \mathrm{a} .{ }^{10}$ In keeping with $\mathrm{H} 3 \mathrm{a}$, the coefficient for previous inclusion is large, which suggests that the likelihood of transitions is much higher if a country has previously had inclusion. By contrast, there is much less evidence for an effect of time at inclusion, and the polynomial terms are not jointly statistically significant (not shown). With regards to H4, we find a large positive coefficient

\footnotetext{
${ }^{10}$ In the supplementary appendix, we show that our substantive results do not change when we replace the binary democracy measures with the full Polity scale or alternative democracy measures from the V-dem project.
} 
for leader change. This suggests that expansion of a coalition to ethnic inclusion is much more likely in these situations, and that we rarely have transitions under the same ruling leader. For post-conflict periods we find a positive coefficient, consistent with $\mathrm{H} 4$, but the coefficient is not statistically significant. For ongoing civil war we find a negative and insignificant coefficient. Of the remaining control variables, both GDP per capita and population size have negative coefficients, but neither is statistically significant. In sum, there is some support for domestic factors affecting the likelihood of transitions to inclusion, as ethnic diversity, episodes of leader change, and previous inclusion make transition more likely, but the effects of political stability in terms of civil conflict and democracy are at best modest.

Turning to transitions from inclusion to exclusion, the second column reveals much fewer consistent influences. The negative sign for ELF indicates a symmetric effect, in that transitions away from inclusion to exclusion are much less likely in more diverse countries, thus corroborating H1b. Consistent with H4 we find a positive coefficient for leader change, which suggests that these also make exclusive shifts more likely. The signs for democracy, post-conflict periods and ongoing civil war are consistent but not significant. None of the other factors are statistically significant, including previous exclusion. Moreover, the estimate for the intercept is considerably larger than for inclusion, indicating generally higher baseline transition probabilities. ${ }^{11}$

In the first column of Table 3 we expand the CPM to form the OPM by adding a term for inclusion at the global level, not counting observation $i$ itself (see H5a). ${ }^{12}$ This addition returns a

\footnotetext{
${ }^{11}$ We have also considered a number of alternative specifications, but found no evidence that these changed the main findings or improved model fit. Again, we found no evidence for a clear relationship between time since conflict and transitions. There is no evidence for transitions being more common following elections or transitions to democracy.

${ }^{12}$ The model stipulates transition probabilities conditional on pre-determined levels among reference units rather than a fully spatial model of simultaneous transitions. For inclusion/exclusion, simultaneous transitions are rare-less than $10 \%$ of transitions to inclusion occur in the presence of a simultaneous transition in a neighboring state, and less than $2 \%$ of observations with a transition to inclusion in a connected state actually see a transition. Simultaneity could also be an issue if we expected strategic behavior where countries enact transition in anticipation of others, but this does
} 
positive coefficient, which implies that countries may be more likely to see transitions when the global level of inclusion is higher. In the second and third column of Table 3 we consider a term comparing inclusion among neighbors within a $500 \mathrm{~km}$ buffer (H6a) and a term indicating the proportion of inclusion within the geographical regions, respectively. Both coefficients are positive and highly statistically significant. The other results do not change notably when adding expanding the CPM to an OPM, save for that the post-conflict term becomes marginally significant in some specifications. Hence, the transnational features seem to capture something distinct from the purely domestic characteristics.

While indicatating that it is possible to find evidence consistent with all of the three different levels, the above results do not directly speak to whether one level is more relevant than another. The global level of inclusion has the highest coefficient, but the model for regional inclusion has a lower log likelihood or better overall fit. Comparing the individual models also does not allow considering the degree of overlap or complementarity between the measures.

In column four we add all the terms to the model simultaneously. The coefficient for regional inclusion remains positive and statistically significant, while the coefficient for neighboring inclusion is reduced noticeably in size. The coefficient for global inclusion remains large, but the standard error is also large, which reflects a much less consistent influence. ${ }^{13}$ We see these results as suggesting that the relevant linkages for ethnic inclusion are not fully global, but broader than the relations to immediate neighboring countries that have been stressed in some studies of diffusion in transitions to democracy. This is consistent with the idea that governments base their approach to ethnic inclusion on expectations shaped by other countries in larger regions, and a possible influence not seem applicable here. Finally, it is difficult to include temporal autocorrelation in spatial limited dependent variable models. We consider only first order transitions. Higher-order transition models tend to be overparameterized, and rarely fit better than first order models (Berchtold \& Raftery, 2002), controlling for time at state.

${ }^{13}$ The term for global proportion could plausibly be associated with time trends. However, estimating the model with a linear time trend yields a positive but not significant coefficient, and does not change the conclusion for the other level of inclusion terms. 
Table 3: Open Polity Model of Transitions

\begin{tabular}{|c|c|c|c|c|c|c|c|c|}
\hline & \multicolumn{8}{|c|}{ Dependent variable: } \\
\hline & \multicolumn{4}{|c|}{ Transition to inclusion } & \multicolumn{4}{|c|}{ Transition to exclusion } \\
\hline & $(1)$ & $(2)$ & (3) & (4) & $(5)$ & $(6)$ & (7) & $(8)$ \\
\hline Global inclusion (-i) & $\begin{array}{c}8.359^{* *} \\
(3.031)\end{array}$ & & & $\begin{array}{c}3.141 \\
(3.475)\end{array}$ & $\begin{array}{c}2.801 \\
(3.020)\end{array}$ & & & $\begin{array}{c}3.445 \\
(3.410)\end{array}$ \\
\hline Neigb. inclusion (-i) & & $\begin{array}{c}2.276^{* *} \\
(0.539)\end{array}$ & & $\begin{array}{c}0.830 \\
(0.766)\end{array}$ & & $\begin{array}{l}-0.316 \\
(0.694)\end{array}$ & & $\begin{array}{c}0.420 \\
(0.875)\end{array}$ \\
\hline Regional inclusion(-i) & & & $\begin{array}{c}3.825^{* *} \\
(0.724)\end{array}$ & $\begin{array}{l}2.723^{*} \\
(1.072)\end{array}$ & & & $\begin{array}{l}-0.826 \\
(0.990)\end{array}$ & $\begin{array}{l}-1.825 \\
(1.404)\end{array}$ \\
\hline ELF & $\begin{array}{c}2.786^{* *} \\
(0.711)\end{array}$ & $\begin{array}{c}2.631^{* *} \\
(0.737)\end{array}$ & $\begin{array}{c}3.002^{* *} \\
(0.735)\end{array}$ & $\begin{array}{c}2.868^{* *} \\
(0.763)\end{array}$ & $\begin{array}{c}-2.770^{* *} \\
(0.897)\end{array}$ & $\begin{array}{c}-2.766^{* *} \\
(0.884)\end{array}$ & $\begin{array}{c}-2.682^{* *} \\
(0.886)\end{array}$ & $\begin{array}{c}-2.735^{* *} \\
(0.887)\end{array}$ \\
\hline Democracy & $\begin{array}{l}-0.156 \\
(0.393)\end{array}$ & $\begin{array}{c}0.122 \\
(0.409)\end{array}$ & $\begin{array}{c}0.346 \\
(0.417)\end{array}$ & $\begin{array}{c}0.208 \\
(0.446)\end{array}$ & $\begin{array}{l}-0.408 \\
(0.390)\end{array}$ & $\begin{array}{l}-0.159 \\
(0.383)\end{array}$ & $\begin{array}{l}-0.310 \\
(0.385)\end{array}$ & $\begin{array}{l}-0.176 \\
(0.394)\end{array}$ \\
\hline Leader change & $\begin{array}{c}2.269^{* *} \\
(0.296)\end{array}$ & $\begin{array}{c}2.213^{* *} \\
(0.309)\end{array}$ & $\begin{array}{c}2.385^{* *} \\
(0.308)\end{array}$ & $\begin{array}{c}2.272^{* *} \\
(0.319)\end{array}$ & $\begin{array}{l}1.695^{* *} \\
(0.335)\end{array}$ & $\begin{array}{l}1.521^{* *} \\
(0.345)\end{array}$ & $\begin{array}{l}1.647^{* *} \\
(0.334)\end{array}$ & $\begin{array}{c}1.528^{* *} \\
(0.347)\end{array}$ \\
\hline Postconflict & $\begin{array}{c}0.464 \\
(0.361)\end{array}$ & $\begin{array}{l}0.703^{\dagger} \\
(0.374)\end{array}$ & $\begin{array}{l}0.611^{\dagger} \\
(0.359)\end{array}$ & $\begin{array}{c}0.604 \\
(0.379)\end{array}$ & $\begin{array}{l}-0.102 \\
(0.413)\end{array}$ & $\begin{array}{l}-0.037 \\
(0.413)\end{array}$ & $\begin{array}{l}-0.029 \\
(0.399)\end{array}$ & $\begin{array}{l}-0.144 \\
(0.423)\end{array}$ \\
\hline Ongoing civil war & $\begin{array}{l}-0.038 \\
(0.502)\end{array}$ & $\begin{array}{c}0.015 \\
(0.500)\end{array}$ & $\begin{array}{l}-0.060 \\
(0.487)\end{array}$ & $\begin{array}{l}-0.016 \\
(0.499)\end{array}$ & $\begin{array}{c}0.356 \\
(0.573)\end{array}$ & $\begin{array}{c}0.448 \\
(0.564)\end{array}$ & $\begin{array}{c}0.433 \\
(0.559)\end{array}$ & $\begin{array}{c}0.245 \\
(0.584)\end{array}$ \\
\hline Ln GDP pc & $\begin{array}{l}-0.256 \\
(0.170)\end{array}$ & $\begin{array}{l}-0.151 \\
(0.169)\end{array}$ & $\begin{array}{l}-0.024 \\
(0.173)\end{array}$ & $\begin{array}{l}-0.071 \\
(0.179)\end{array}$ & $\begin{array}{l}-0.173 \\
(0.163)\end{array}$ & $\begin{array}{l}-0.184 \\
(0.172)\end{array}$ & $\begin{array}{l}-0.248 \\
(0.186)\end{array}$ & $\begin{array}{l}-0.301 \\
(0.198)\end{array}$ \\
\hline Ln population & $\begin{array}{l}-0.130 \\
(0.122)\end{array}$ & $\begin{array}{l}-0.139 \\
(0.119)\end{array}$ & $\begin{array}{l}-0.159 \\
(0.118)\end{array}$ & $\begin{array}{l}-0.109 \\
(0.122)\end{array}$ & $\begin{array}{l}-0.214 \\
(0.148)\end{array}$ & $\begin{array}{l}-0.213 \\
(0.154)\end{array}$ & $\begin{array}{c}-0.253^{\dagger} \\
(0.151)\end{array}$ & $\begin{array}{l}-0.220 \\
(0.154)\end{array}$ \\
\hline Previous inclusion & $\begin{array}{c}1.249^{* *} \\
(0.414)\end{array}$ & $\begin{array}{c}1.585^{* *} \\
(0.397)\end{array}$ & $\begin{array}{c}1.300^{* *} \\
(0.389)\end{array}$ & $\begin{array}{l}1.152^{* *} \\
(0.439)\end{array}$ & & & & \\
\hline Previous exclusion & & & & & $\begin{array}{c}0.174 \\
(0.442)\end{array}$ & $\begin{array}{c}0.500 \\
(0.408)\end{array}$ & $\begin{array}{c}0.480 \\
(0.396)\end{array}$ & $\begin{array}{c}0.388 \\
(0.472)\end{array}$ \\
\hline Constant & $\begin{array}{c}-6.424^{* *} \\
(2.045)\end{array}$ & $\begin{array}{c}-5.265^{* *} \\
(1.861)\end{array}$ & $\begin{array}{c}-6.913^{* *} \\
(1.973)\end{array}$ & $\begin{array}{c}-7.748^{* *} \\
(2.230)\end{array}$ & $\begin{array}{l}-0.654 \\
(2.165)\end{array}$ & $\begin{array}{c}0.405 \\
(2.084)\end{array}$ & $\begin{array}{c}1.486 \\
(2.280)\end{array}$ & $\begin{array}{c}0.640 \\
(2.455)\end{array}$ \\
\hline Observations & 3,446 & 3,354 & 3,446 & 3,354 & 2,601 & 2,539 & 2,601 & 2,539 \\
\hline Log Likelihood & -222.555 & -205.946 & -212.034 & -201.272 & -178.055 & -171.792 & -178.134 & -170.799 \\
\hline Akaike Inf. Crit. & 471.111 & 437.892 & 450.069 & 432.545 & 382.110 & 369.584 & 382.268 & 371.598 \\
\hline
\end{tabular}

of regional organizations below the global level. ${ }^{14}$

${ }^{14}$ We have also considered a number of specifications, reflecting alternative mechanisms or possible confounds, but found no evidence that these changed the main findings or improved model fit. First, there is no evidence that countries with transnational ethnic kin were more likely to see transitions, irrespective of whether the kin group is included or not. Second, we could not find any evidence that peacekeeping operations or other external interventions had a clear impact on transitions, or that including these reduced the impact of the inclusion term. Finally, although the 
Turning to transitions to exclusion in the subsequent columns of Table 3, we find much less clear support for strong predictors of exclusive shifts as well as evidence for clear differences between the CPM and the OPM. The term for global inclusion consistently has the wrong sign compared to $\mathrm{H} 5 \mathrm{~b}$, indicating that greater global inclusion makes transitions to exclusion more likely, although the coefficient is not statistically significant. The regional and neighboring terms have the expected negative sign, thus yielding some support for a symmetric effect where countries are less likely to see transitions away from exclusion when direct or regional neighbors have higher rates of inclusion, as anticipated by $\mathrm{H} 6 \mathrm{~b}$ and $\mathrm{H} 7 \mathrm{~b}$, but the coefficients are not statistically significant at conventional levels.

\section{Substantive effects}

Logit coefficients indicate effects on the log odds of the response and are difficult to interpret directly in substantive terms, since the substantive impact on the probabilities of the response depend on the values of all factors affecting the baseline odds. To evaluate the effect of differences in the regional environment on transitions from exclusion to inclusion we estimate the predicted likelihood for a median profile, letting the neighboring and regional environment change from zero to universal inclusion rates. To ensure realistic scenarios we consider the median values for observations with exclusion at $t-1$. The left plot in Figure plots the implied marginal effect, with a $95 \%$ confidence interval for the predicted values, and the transition probability for a profile with the median values among countries with exclusion as a dashed line. Although the likelihood of transitions at the median is very small, there is a strong relative change in the likelihood over variation in the regional context, and transitions become consistently more likely in an environment with more inclusion.

Turning to transitions from inclusion to exclusion, we find similar results, where transitions to European Union may respond to ethnic discrimination (e.g., Kreutz, 2015), these actions are not associated with a consistent higher likelihood of transitions. 
Figure 3: Transitions to inclusion/exclusion by regional contact, OPM
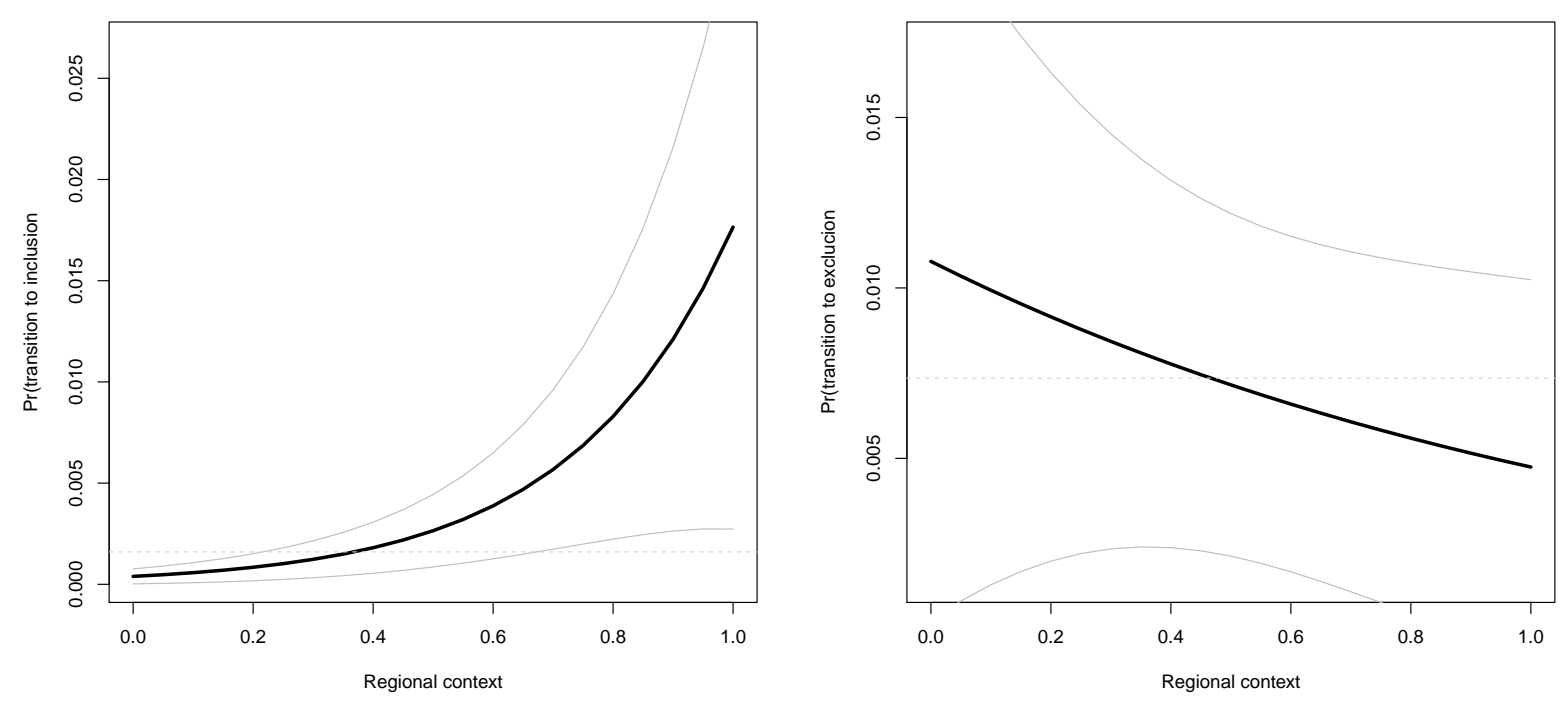

exclusion become less likely in a local environment with higher rates of inclusion. However, the error bands are much wider in this case than in the case of transitions to inclusion. Note also that the higher constant term implies a higher likelihood of transitions, possibly indicating greater volatility in transitions to exclusion depending on whether smaller groups are included or not.

\section{Case illustrations}

Rather than affecting the entire world evenly, the regional effect driving inclusion operates especially strongly in two sets of cases. First, when the European Union started negotiating its eastern enlargement in the 1990s, it made both future aid and membership conditional on democratic norms that included minority rights and power sharing. As shown by Wilkinson (2005), this commitment to consociational principles of ethnic proportionality was explicitly incorporated into the conditionality principles and prompted policy changes in several cases. While improvements of minority rights benefited the Russians in Latvia and Estonia without bringing about power sharing per se, EU pressure helped bring about more inclusive rule in Romania and Bulgaria. Furthermore, it is likely 
that regional "top-down" diffusion made a big difference, because these transitions to inclusion occurred despite considerable domestic opposition (see also Brusis, 2003; Kelley, 2004). It is hardly surprising that our data record inclusive shifts in Slovakia, Bulgaria and Romania along these lines, although subsequently, there have been transitions away from inclusion. These reversals suggest that "inclusion from above" through EU conditionality may not be sustainable in the long run.

Another important set of cases can be found in Sub-Saharan Africa, which is the part of the world that has experienced the largest and most important increases in power sharing in recent years (Mehler, 2009; Cheeseman, 2011). More than any other event, the successful adoption of power sharing in South Africa after the fall of the Apartheid system reinforced this norm, promoted by the global saliency of the struggle against the racist regime. Even though the 1994 transition in South Africa is normally thought of as an instance of democratization, the end of racial discrimination ushered in shared rule along consociational lines that was directly inspired by Lijphart's own writings on South Africa (Vandeginste, 2009).

The fall of socialism had a dramatic impact on the aims and strategies of both sides in the South African conflict. Until the end of the Cold War, the African National Congress (ANC) aspired to establish a socialist one-party state similar to those in power in most of its neighboring countries rather than a liberal democracy or system of power sharing. After the Soviet Union stopped funding the ANC in 1989, a negotiated transition with power-sharing similar to the 1979 Lancaster House Agreement in Zimbabwe became a more attractive option. Internal documents from the ANC explicitly acknowledge the impact on their strategy and aims: ${ }^{15}$

our historic conjuncture of the 1994 democratic breakthrough took place against the backdrop of ...the demise of socialism in the Soviet Union ... [which] altered completely the balance of forces in favor of imperialism (p. 160) ... The collapse of

\footnotetext{
${ }^{15}$ http://www.anc.org.za/docs/umrabulo/2015/ngc_disc_docsy.pdf
} 
... socialism influenced our transition towards the negotiated political settlement in our country (p. 189).

With regards to the National Party, the last white president de Klerk also notes that "the collapse of the Soviet Union helped to remove our long-standing concern regarding the influence of the South African Communist Party ...". ${ }^{16}$ The decline in fear of communism in the region also decreased the willingness of key actors in Western states to overlook the Apartheid regime, and helped remove barriers to international pressure for reform.

After this important breakthrough, South African politicians such as Mandela and Mbeki played a prominent role as enthusiastic promoters of power sharing in their capacity as mediators in post-conflict situations in other parts of the Africa (Curtis, 2006), a role that was also assumed by other African statesmen (Cheeseman, 2011). After the death of Julius Nyerere, Nelson Mandela took the lead in the negotiations that ended the Burundian civil war with the Arusha peace agreement in 2000 (Vandeginste, 2009). According to Lemarchand (2006), his strong commitment to ethnic inclusion influenced the outcome of the peace negotiations decisively in a consociational direction. In the early 1990s, an earlier attempt to share power had been cut short by a Tutsi military coup that produced widespread political violence and volatility until the end of the decade. In 1996, the OAU imposed sanctions on the coup-maker Pierre Buyoya, which increased the regional pressure on the ethnically exclusive regime (Mehler, 2013, 33). Unfortunately, while representing a major improvement over the violent 1990s, the power-sharing deal has failed to deliver long-term stability in Burundi. While the terms of Arusha are still formally valid, violent political protest flared up in 2015, followed by a failed coup attempt. However, so far, ethnic inclusion has helped prevent the recurrence of full-fledged civil war.

Liberia constitutes another clear example of transnational factors facilitating transitions to

\footnotetext{
${ }^{16}$ Speech delivered at Stanford University, 29 January 2001, http://news. stanford. edu/news/2001/january31/deklerk-131.html.
} 
power-sharing (Adebajo, 2002; Ero, 1995; Sesay, 1996). Like the long-lasting conflict in Burundi, the Liberian civil war was in many senses a classical example of a conflict driven by competing claims for ethnic dominance. Since its foundation in 1847, Liberia was dominated by the Americo-Liberians, i.e., descendants of the freed slave settlers, despite constituting a very small share of the total population (only 2\% in 1946). The 1980 coup by Samuel Doe transferred political dominance to the Krahn. The 1989 revolt by Charles Taylor pitted an alliance between the Americo-Liberians, Gio, and Mano against the Krahn and Mandingo. Whereas the UN and the OAU failed to provide a response to the conflict, a 1990 summit by the Economic Community of West African States (ECOWAS) set up a committee to promote a settlement and deploy a multinational peacekeeping force to Liberia, explicitly calling for "a broad-based interim government." Although the armed conflict continued, the international efforts helped facilitate the parties agreeing to a peace agreement and transnational government with participation by the different parties.

Although it is easy to find overt international influences in cases with direct foreign interventions, most transition to inclusion have taken place outside peacekeeping and foreign initiated negotiations. Guinea provides an example where international factors played a plausible facilitating role in promoting a transition to ethnic inclusion, even in the absence of overt intervention. Prior to 2008, the central government in Guinea had remained remarkably stable since independence, despite widespread instability and change in neighboring states (Arieff, 2009). The death of President Conté (in power since 1984) was followed by a coup, which unleashed a period of violent instability. Following voluntary mediation by the president of Burkina-Faso, the main parties agreed to a transition framework, which gave way to ethnic power sharing between all the relevant groups in the country (Witt, 2013). Although it is difficult to evaluate counterfactuals about transnational influences, a recognition of the benefits of inclusion in other states in the region likely supported the agreement to share power, and the likelihood of external condemnation and sanctions deterred efforts to strive for exclusive dominance (see also Marinov \& Goemans, 2014). 
Of course, power-sharing arrangements in Sub-Saharan Africa have often been far from stable, as illustrated by recent events in Burundi and the break-up of the Sudan, following the externally prompted adoption of power sharing in 2006. In this part of the world, many regimes suffer from instability that may trigger infighting and conflict recurrence (Spears, 2002; Roessler, 2011). Yet, despite occasional reversals to instability and exclusion, our findings suggest that this does not prevent power sharing from gradually gaining ground in Sub-Saharan Africa, and our findings also suggest that if initial transitions to inclusion fail, they are more likely to be followed by a return to inclusion later.

\section{Conclusion}

Starting from the asserted importance of ethnic inclusion for the prospects of peace, the main aim of this article has been to increase causal depth by examining the factors that affect where and when governments shift from ethnic dominance to inclusion. As anticipated, these determinants can be found both within and outside the state. While previous studies have focused on domestic explanations, we have found strong evidence of a diffusion effect within regional contexts. Significantly, however, we have not been able to confirm any consistent spread at the global level, thus casting doubt on sweeping theories of an emerging world polity. The support for diffusion among contiguous states is also weaker than expected. To some extent, these effects can also be found in the opposite direction, from inclusion to exclusion, thus suggesting that there is a potential lock-in effect that prevents single countries in regions dominated by ethnic exclusion from adopting power sharing.

Contrary to ethnic diversity or other structural factors that are almost entirely beyond manipulation in the short run, inclusion is inherently a policy choice that can in principle be influenced. From a policy-making perspective, this makes our findings about the open-polity dimension particularly good news, since fostering power sharing and inclusion in one country is likely to have positive 
externalities in neighboring countries by raising the odds of similar arrangements being adopted there too. There may even be regional "tipping phenomena," otherwise seen in connection with democratization and the adoption of norms. Sub-Saharan Africa appears to have experienced such a wave of inclusion since the Cold War. Obviously, the open-polity perspective presented in this paper shows that such snowballing effects could also feature illiberal waves toward ethnic dominance. For example, following the rise of right-wing populism targeting multi-ethnic and globalized governance, a drastic weakening of the European Union could remove critical pressures on members states in Eastern Europe, thus eroding the support for ethnic inclusion. We have already noted that the organization's liberal influence may be waning in Eastern Europe.

Given the link between exclusion and conflict, it is conceivable that the spread of inclusion helps to account for regions of peace as well. However, as we have highlighted, this is no one-way street. Spatial processes that operate in the opposite direct - shifts toward exclusion - ultimately risk creating not only clustering of exclusion, but also conflict, as illustrated by the Middle East.

Of course, we do not expect this analysis to be the final word on what explains ethnic inclusion. Future research will have to further unpack the causal mechanisms driving decisions to abandon or adopt exclusive practices. To be sure, we have made no empirical effort to distinguish between explanations that draw on emulation and learning. Nor have we attempted to separate those that stress voluntary demonstration effects from those that depend on international pressure through international organizations or great powers. For example, additional analysis is needed to tell whether the diffusion effects in Sub-Saharan Africa are driven by regional organizations, such as the African Union, or more informally organized post-conflict intervention offered by regional leaders volunteering as mediators.

While we have controlled for previous conflict, the endogenous relationship between exclusion and conflict would also need to be further analyzed. There is strong evidence suggesting that leaders in post-colonial states typically include those groups that are seen as potentially threatening, but 
these results have not yet been extended to other parts of the world (Wucherpfennig, Hunziker \& Cederman, 2016). To fully endogenize inclusion and conflict, it would be useful to disaggregate the analysis of diffusion effects to the group level. This would also render possible a more nuanced analysis of mechanisms relating to transborder ethnic kin and irredentism.

For now, we conclude that our initial exploration of how inclusion spreads has yielded promising results that call for more research. In light of these findings, it will prove difficult to uphold the assumption that state elites make choices between ethnic dominance and inclusion without considering the conditions in their neighborhoods, very much as leaders do not appear to democratize their polities without looking across their own state borders. 


\section{Acknowledgements}

Previous versions of this manuscripts have been presented at the European Network for Conflict Research (ENCoRe) in Geneva, January 21-22, 2016 and the American Political Science Association in San Francisco, September 1-4, 2015. We thank Victor Asal and the other participants for their comments and suggestions.

\section{Declaration of Conflicting Interests}

The authors declared no potential conflicts of interest with respect to the research, authorship, and/or publication of this article.

\section{Funding}

The authors disclosed receipt of the following financial support for the research, authorship, and/or publication of this article: Gleditsch acknowledges the support of the European Research Council (313373) and the Research Council of Norway (213535/F10). 


\section{References}

Acharya, A. (2004). Whose norms matter? Norm localization and institutional change in Asian regionalism. International Organization, 58(3), 239-275.

Adebajo, A. (2002). Liberia's civil war: Nigeria, ECOMOG, and regional security in West Africa. Boulder, CO: Lynne Rienner.

Arieff, A. (2009). Still standing: Neighbourhood wars and political stability in Guinea. Journal Of Modern African Studies, 47(3), 331-348.

Beissinger, M. R. (2007). Structure and example in modular political phenomena: The diffusion of Bulldozer/Rose/Orange/Tulip revolutions. Perspectives on Politics, 5(2), 259-276.

Bell, S. R., Bhasin, T., Clay, K. C. \& Murdie, A. (2014). Taking the fight to them: Neighborhood human rights organizations and domestic protest. British Journal of Political Science, 44(4), $853-875$.

Berchtold, A. \& Raftery, A. (2002). The mixture transition distribution model for high-order Markov chains and non-Gaussian time series. Statistical Science, 17(3), 328-356.

Bergstrand, J. H. (1985). The gravity equation in international trade: Some microeconomic foundations and empirical evidence. Review of Economics and Statistics, 67(3), 474-481.

Birnir, J. K., \& Waguespack, D.M. (2011). Ethnic inclusion and economic growth. Party Politics, 17(2), 243-260.

Brusis, M. (2003). The European Union and interethnic power-sharing arrangements in accession countries. Journal of Ethnopolitics and Minority Issues in Europe, (1), 1-19.

Cammett, M. C. (2011). Partisan activism and access to welfare in Lebanon. Studies in Comparative International Development, 46(1), 70-97. 
Cammett, M. \& Malesky, E. (2012). Power sharing in postconflict societies: Implications for peace and governance. Journal of Conflict Resolution, 56(6), 982-1016.

Carter, D. B. \& Signorino, C. S. (2010). Back to the future: Modeling time dependence in binary data. Political Analysis, 18(3), 271-292.

Cederman, L.-E., Gleditsch, K. S. \& Buhaug, H. (2013). Inequality, grievances and civil war. New York, NY: Cambridge University Press.

Cederman, L.-E., Gleditsch, K. S. \& Wucherpfennig, J. (2017). Predicting the decline of ethnic conflict: Was Gurr right and for the right reasons?. Journal of Peace Research, 54(2), 262-274.

Cederman, L.-E., Wimmer, A. \& Min, B. (2010). Why do ethnic groups rebel? New data and analysis. World Politics, 62(1), 87-119.

Cheeseman, N. (2011). The internal dynamics of power-sharing in Africa. Democratization, 18(2), 336-365.

Connor, W. (1994). Ethnonationalism: The quest for understanding. Princeton, NJ: Princeton University Press.

Curtis, D. (2006). The South African approach to peacebuilding in the Great Lakes region of Africa. In Constitutionalism and democratic transitions: Lessons from South Africa, ed. Federico, V. \& Fusaro, C. Florence: Firenze University Press, pp. 153-176.

Dahl, R. A. (1971). Polyarchy: Participation and opposition. New Haven, CT: Yale University Press.

Diamond, L. J. 1994. Toward democratic consolidation. Journal of Democracy, 5(1), 4-17.

Dobbin, F., Simmons, B. A. \& Garrett, G. (2006). The global diffusion of public policies: Social construction, coercion, competition, or learning? Annual Review of Sociology, 33, 449-472. 
Ero, C. (1995). ECOWAS and the subregional peacekeeping in Liberia. Journal of Humanitarian Assistance 66, https://sites.tufts.edu/jha/archives/66.

Fearon, J. D. (1998). Commitment problems and the spread of ethnic conflict. In The international spread of ethnic conflict, ed. Lake, D. A. \& Rothchild, D. Princeton, NJ: Princeton University Press.

Finnemore, M. \& Sikkink, K. (1998). International norm dynamics and political change. International Organization, 52(4), 887-917.

Geertz, C. 1963. The integrative revolution: Primordial sentiments and civil politics in the new states. In Old societies and new states: The quest for modernity in Asia and Africa, ed. Geertz, C. New York: Free Press.

Gellner, E. (1983). Nations and nationalism. Ithaca, NY: Cornell University Press.

Gleditsch, K. S. (2002). Expanded trade and GDP data, 1946-99. Journal of Conflict Resolution, $46(5), 712-724$.

Gleditsch, K. S. \& Ward, M. D. (2006). The diffusion of democracy and the international context of democratization. International Organization, 60(4), 911-933.

Goemans, H. E., Gleditsch, K. S., \& Chiozza, G. (2009). Introducing Archigos: A data set of political leaders. Journal of Peace Research, 46(2), 269-283.

Gurr, T. R. (2000a). Ethnic warfare on the wane. Foreign Affairs, 79(May/June), 52-64.

Gurr, T. R. (2000b). Peoples versus states: Minorities at risk in the new century. Washington, DC: United States Institute of Peace Press.

Hartzell, C. \& Hoddie, M. (2007). Crafting peace: Power-sharing institutions and the negotiated settlement of civil wars. University Park, PA: Pennsylvania State University Press. 
Hechter, M. (2000). Containing nationalism. Oxford: Oxford University Press.

Hirschman, A. O. (1964). The Paternity of an Index. American Economic Review, 54(5), 761.

Huntington, S. P. (1991). The third wave: Democratization in the late twentieth century. Norman, OK: Oklahoma University Press.

Jaggers, K. \& Gurr, T. R. (1995). Tracking democracy's 'third wave' with the Polity III data. Journal of Peace Research, 32(4), 469-82.

Kelley, J. G. (2004). Ethnic politics in Europe: The power of norms and incentives. Princeton, NJ: University of Princeton Press.

Kopstein, J. S., \& Reilly, D. A. (2000). Geographic diffusion of the transformation of the postcommunist world. World Politics, 53(1), 1-37.

Kreutz, J. (2015). Human rights, geostrategy, and EU foreign policy, 1989-2008. International Organization, 69(1), 195-217.

Kuran, T. (1991). Now out of never: The element of surprise in the East European revolution of 1989. World Politics, 44(1), 7-48.

Kuran, T. (1998). Ethnic dissimilation and its international diffusion. In The international spread of ethnic conflict, ed. Lake, D. A. \& Rothchild, D. Princeton, NJ: Princeton University Press.

Lemarchand, R. (2006). Consociationalism and power sharing in Africa: Rwanda, Burundi, and the Democratic Republic of the Congo. African Affairs, 106(1), 1-20.

Lijphart, A. (1977). Democracy in plural societies: A comparative exploration. New Haven, CT: Yale University Press.

Marinov, N. \& Goemans, H. E. (2014). Coups and democracy. British Journal of Political Science, 44(4), 799-825. 
Mattes, M., \& Savun, B. (2009). Fostering peace after civil war: Commitment problems and agreement design. International Studies Quarterly, 53(3), 737-759.

McGarry, J. \& O’Leary, B. (2009). Must pluri-national federations fail? Ethnopolitics, 8(1), 5-25.

Mehler, A. (2009). Introduction: Power-sharing in Africa. Africa Spectrum, 3(1), 2-10.

Mehler, A. (2013). Consociationalism for weaklings, autocracy for muscle men? Determinants of constitutional reform in divided societies. Civil Wars, 1(1), 21-43.

Mehler, A. (2016). Adapted instead of imported: Peacebuildling by power-sharing. In Peacebuilding in crisis: Rethinking paradigms and practices of transnational cooperation, ed. Debiel, T., Held, T \& Schneckener, U. Abingdon: Routledge.

Meyer, J. W., Boli, J., Thomas, G. M., \& Ramirez, F. O. (1997). World society and the nation-state. American Journal of Sociology, 103(1), 144-181.

Mueller, J. (1999). Capitalism, democracy, and Ralph's Pretty Good Grocery. Princeton, NJ: Princeton University Press.

Mylonas, H. (2012). The politics of nation-building: Making co-nations, refugees, and minorities. New York: Cambridge University Press.

O’Loughlin, J. V., Ward, M. D., Lofdahl, C. L., Cohen, J. S., Brown, D., Reilly, D, Gleditsch, K. S., \& Shin, M. A. (1998). The diffusion of democracy, 1946-1994. Annals of the Association of American Geographers, 88(4), 545-574.

Petersen, R. D. (2002). Understanding ethnic violence: Fear, hatred, and resentment in twentieth-Century Eastern Europe. Cambridge: Cambridge University Press.

Pevehouse, J. (2005). Democracy from above: Regional organizations and democratization. Cambridge: Cambridge University Press. 
Powers, K. \& Goertz, G. (2011). The economic-institutional construction of regions: Conceptualisation and operationalisation. Review of International Studies, 37(5), 2387-2415.

Roessler, P. G. (2011). The enemy from within: Personal rule, coups, and civil wars in Africa. World Politics, 53(2), 300-346.

Rothchild, D. \& Foley, M. W. (1988). African states and the politics of inclusive coalitions. Boulder, CO: Westview Press.

Russett, B. M. (1967). International regions and the international system: A study in political ecology. Chicago, IL: Rand McNally.

Schelling, T. C. 1971. Dynamic models of segregation. Journal of Mathematical Sociology, 1(2), $143-186$.

Sesay, M. A. (1996). Civil war and collective intervention in Liberia. Review of African Political Economy, 23(67), 35-52.

Simmons, B. A. \& Elkins, Z. (2004). The globalization of liberalization: Policy diffusion in the international political economy. American Political Science Review, 98(1), 171-189.

Spears, I. S. (2002). Africa: The limits of power-sharing. Journal of Democracy, 13(3), 123-136.

Spruyt, H. (1994). The sovereign state and its competitors: An analysis of systems change. Princeton, NJ: Princeton University Press.

Starr, H. (1991). Democratic dominoes: Diffusion approaches to the spread of democracy in the international system. Journal of Conflict Resolution, 35(2), 356-381.

Stedman, S. J. (1997). Spoiler problems in peace processes. International Security, 22(2), 5-53.

Vandeginste, S. (2009). Power-sharing, conflict and transition in Burundi: Twenty years of trial and error. Africa Spectrum, 3, 63-86. 
Weidmann, N. B., Kuse, D., \& Gleditsch, K. S. (2010). The geography of the international system: The Cshapes dataset. International Interactions, 36(1), 86-106.

Weiner, M. (1971). The Macedonian syndrome: An historical model of international relations and political development. World Politics, 23(4), 665-683.

Wilkinson, S. I. (2005). Conditionality, consociationalism, and the European Union. In From power sharing to democracy: Post-conflict institutions in ethnically divided societies, ed. Noel, S. Mc-Gill-Queens University Press, pp. 239-262.

Wimmer, A. (2015). "Nation building: A long-term perspective and global analysis. European Sociological Review, 31(1), 30-47.

Witt, A. (2013). Convergence on whose terms? Reacting to coups d'etat in Guinea and Madagascar. African Security, 6(3-4), 257-275.

Wucherpfennig, J., Hunziker, P., \& Cederman, L.-E. (2016). Who inherits the State? Colonial rule and post-colonial conflict. American Journal of Political Science, 60(4), 882-898.

Wucherpfennig, J., Metternich, N. W., Cederman, L.-E. \& K. S. Gleditsch. (2012). Ethnicity, the state, and the duration of civil wars. World Politics, 64(1), 79-115.

\section{Author biographies}

Lars-Erik Cederman is Professor of International Conflict Research, ETH Zürich. Current research interests: ethnicity, nationalism, democratization, and political violence. Most recent book: Inequality, Grievances, and Civil War (Cambridge University Press 2013, with Kristian Skrede Gleditsch and Halvard Buhaug). 
Kristian Skrede Gleditsch is Professor, Department of Government, University of Essex and Research Associate, Peace Research Institute Oslo. Current research interests: violent and non-violent conflict, democratization, and political violence. Most recent book: Inequality, Grievances, and Civil War (Cambridge University Press 2013, with Lars-Erik Cederman and Halvard Buhaug).

Julian Wucherpfennig is Assistant Professor, Hertie School of Governance (2016- ). Current research interests: powersharing and civil war, conflict processes and political violence. Recent publications have appeared in the American Political Science Review and the American Journal of Political Science. 